\title{
Journal of Bone Biology and Osteoporosis Cutting Edge of Herbal Drugs over Allopathic Drugs in Clinical Treatment of Rheumatoid Arthritis
}

\author{
Nimesh S and Ashwlayan VD*
}

\author{
Department of Pharmaceutical Technology, Meerut Institute of Engineering and Technology, India
}

*Correspondence: Vrish Dhwaj Ashwlayan, Department of Pharmaceutical Technology, Meerut Institute of Engineering and Technology, NH-58 Baghpat Crossing Bypass Road, Meerut-250005 (U. P.), India, Tel: 91 9412493228; Fax: 91-121-2439058; E-mail: vrish.ashwlayan@miet.ac.in

Rec date: June 23, 2018; Acc date: July 20, 2018; Pub date: July 25, 2018

\begin{abstract}
Rheumatoid arthritis (RA) is a chronic inflammatory and systemic auto immune disease, affecting people predominantly between the ages of $20-60$ years with unpredictable course. About $1 \%$ of the world's population is afflicted by rheumatoid arthritis and is two to three times more common in women than men. This is a long lasting disease that can affect joints in any part of the body, most commonly the hands, wrists, and knees. Popularity of medicinal plants is increasing day by day due to side effects of allopathic medicines. Herbal medicinal plants have been used as major sources of cure of human diseases since time immemorial. Today, one fourth of world population depends on traditional medicine and $80 \%$ of the population relies on indigenous herbal medicinal plants. Even today most of the people live in different developing countries depend on the plant derived medicines for the first line of primary health care because of least or no side effects.
\end{abstract}

Keywords: Rheumatoid arthritis, Freund's adjuvant, Aetiology, Biological agents, Treatment, Side-effect, Herbal drug

Abbreviations: Ad: Asystasia dalzelliana; Ai: Acalypha indica; ALP: Alkaline Phosphatise; anti-CCP: anti-Cyclic Citrullinated Peptide; At: Azima tetracantha; CFA: Complete Freund's Adjuvant; CRP: C-Reactive Protein; Cu: Cassia uniflora; CZ: Cinnamomum Zeyllanicum; DMARDs: Disease-Modifying Anti-Rheumatic Drugs; DMSO: Dimethylsulphoxide; ESR: Erythrocyte Sedimentation Rat; FA: Flavonoids aglycones; GF: Genkwa Flos; GIT: Gastro-Intestinal Tract; Hb: Haemoglobin; Hi: Hemidesmus indicus; Hp: Holarrhena pubescens; HRBC: Human Red Blood Cell; IC 50 Inhibitory Concentration-50; IgG: immunoglobulin G; IL: interleukins; La: Leucas aspera; MRI: Magnetic Resonance Imaging; NSAIDs: Non-Steroidal Anti-Inflammatory Drugs; Pa: Phyllanthus amarus; RA: Rheumatoid Arthritis; RBC: Red Blood Cell; SGOT: Serum Glutamate Oxaloacetate Transaminase; SGPT: Serum Glutamate Pyruvate Transaminase; Sr: Sida rhombifolia; TAPP: Type-A Procyanidine Polyphenols; TNF-alpha: Tumor Necrosis Factor-a; WBC: White Blood Cell; Wc: Wedelia calendulacea; WHO: World Health Organization

\section{Introduction}

Immune system of our body plays a crucial role, as an overactive immune system may lead to certain fatal disease because of various hypersensitive or allergic reactions which may cause numerous derangements; loss of normal capacity to differentiate self from nonself-resulting in immune reactions against our own cells and tissues called autoimmune diseases. Certain common autoimmune diseases like myasthenia gravis, serum sickness, pernicious anaemia, reactive arthritis etc., are the severe issues for medical and pharmaceutical community 
because of unknown aetiology [1]. According to World Health Organization (WHO), $0.3-1 \%$ of the world population is affected from rheumatoid arthritis (RA) and among them females are three times more prone to the disease as compared to males [2]. RA is a chronic, inflammatory, and systemic autoimmune disease [3]. The primary symptoms of RA include pain, swelling, and destruction of cartilage and bone as a result of which permanent disability occurs. Although the exact aetiology is unknown but several hypotheses said that it is triggered by the combination of genetic predisposition and exposure to environmental factors like viruses [4]. The exact Pathophysiology is still unknown but release of certain free radicals such as nitrous oxide and superoxide radicals generated as byproducts of cellular metabolism. The release of such free radicals may induce the production of interleukins (IL) and tumor necrosis factor (TNF-a) from T-cells which ultimately influence the production of growth factors, cytokines and Adhesive molecules on immune cells as such factors may cause tissue destruction and inflammation (Figure 1).

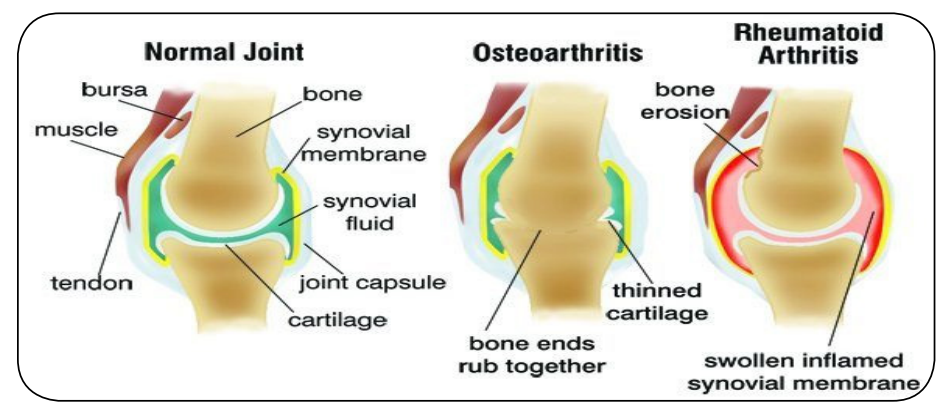

Figure 1: Normal joint \& Rheumatoid Arthritis affect joint.

Pathological changes in RA are hyperplasia of synovial membrane, infiltration of inflammatory cells and neovascularisation, which result into cartilage erosion and articular destruction [5]. The goal of treatment for rheumatoid arthritis patients are to eliminate symptoms, slow disease progression, and optimize quality of life [6]. Therefore, before starting the treatment of RA certain goals must be kept in mind such as relief of algesia, reduction of inflammation, protection of articular structure, maintenance of function and control of systemic involvement [7].

\section{Classification}

Rheumatoid Arthritis can be classified as:

- Palindromic rheumatoid arthritis

- Juvenile rheumatoid arthritis

- Rheumatoid spondylitis

- Other types of arthritis
- Osteoarthritis

- Primary osteoarthritis - It occurs in elder persons.

- Secondary osteoarthritis - It occurs at any stage.

- Ankylosing spondylarthritis

- Infectious arthritis

- Supportive arthritis

- Tuberculous arthritis

- Lyme arthritis

- Viral arthritis

- Gout arthritis

\section{Aetiology}

Arthritis involves the breakdown of cartilage. Cartilage normally protects a joint, allowing it to move smoothly. The process produces an inflammatory response of the synovial (sinusitis) secondary to hyperplasia of synovial cells, excess synovial fluid, and the development of pain in the synovial. The pathology of the disease process often leads to the destruction of articular cartilage and alkalosis of the joints. Rheumatoid arthritis can also produce diffuse inflammation in the lungs, pericardium, pleura, and sclera, and also nodular lesions most common in subcutaneous tissue. Although the cause of rheumatoid arthritis is unknown, autoimmunity plays a pivotal role in both its chronicity and progression, and RA is considered a systemic autoimmune disease [8].

\section{Epidemiology}

About $1 \%$ of the world's population is afflicted by rheumatoid arthritis, women three times more often than men [9]. Arthritis represents one of the most prevalent chronic health problems and is a leading cause of disability. Arthritis affected 43 million U.S. Adults in 2002 and by the year 2020, this number is expected to reach 60 million [10]. It is up to three times more common in smokers than nonsmokers, particularly in men, heavy smokers, and those who are rheumatoid factor positive. A study in 2010 found that those who drank modest amounts of alcohol regularly were four times less likely to get rheumatoid arthritis than those who never drank [11].

\section{Sign \& symptoms}

Symptoms of arthritis are gradually developed. The first symptoms are often felt in small joints, i.e. fingers and toes, although shoulders and knees can be affected early, and muscle stiffness can be a prominent early feature [12]. Symptoms of RA include

1. Morning stiffness that last for at least $1 \mathrm{hr}$.

2. Joint pain with warmth, swelling, tenderness and 
stiffness of the joint after resting

3. Low-grade fever.

4. Inflammation of small blood vessels can cause small nodules under the skin, but they are generally painless.

\section{Pathophysiology of RA}

RA is associated with several genetic and environmental factors that contribute the phenotype in different combinations (Figure 2).

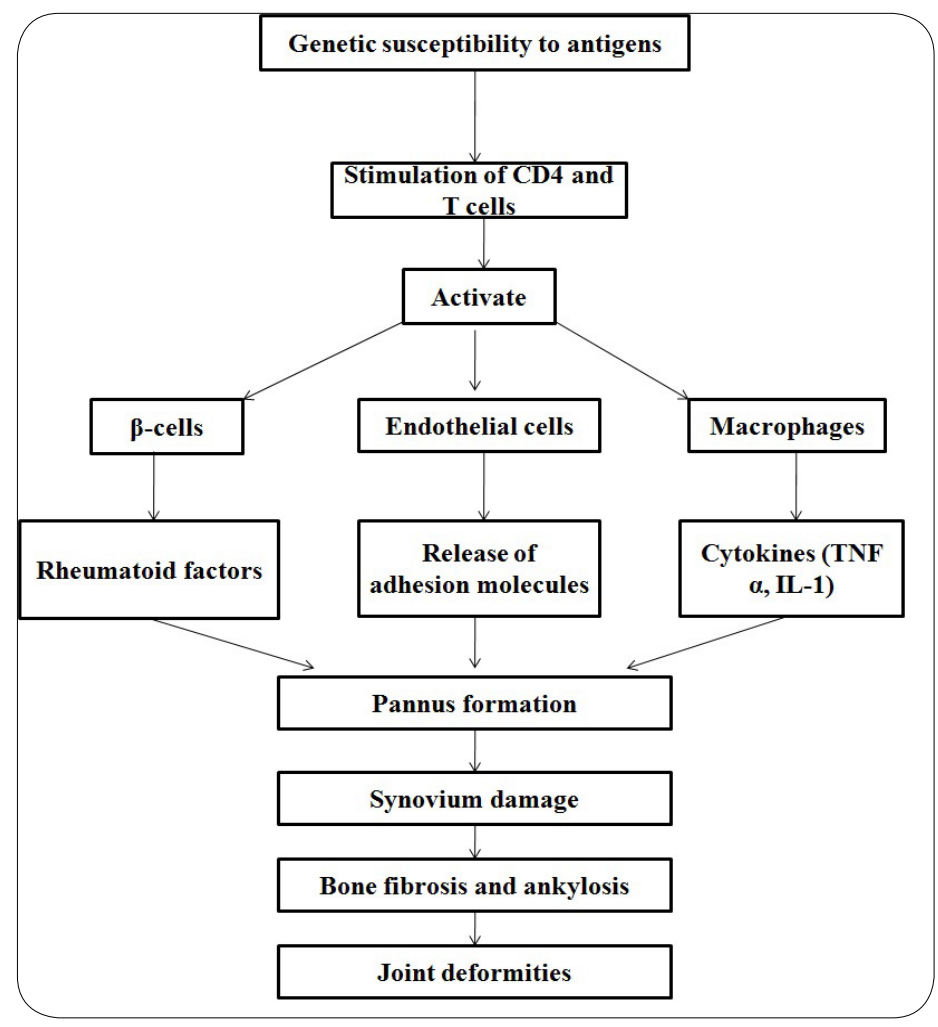

Figure 2: Possible molecular mechanism for arthritis.

RA is initiated by immune complexes and complement system, perpetuated by cytokines, and affected by metalloproteinase [13]. Antigen-activated CD4+ T cells stimulate monocytes, macrophages, and synovial fibroblasts which in turn lead to the production of cytokines interleukin-1, interleukin-6, and TNF- $a$ and secretion of matrix metalloproteinase through cell-surface signalling [14]. In early RA, large amount of neutrophils are present in synovial fluid [15]. Chronically, hypertrophy and hyperplasia form projections into the joint capsule. Immune complexes found in the synovial fluid often are immunoglobulin G (IgG) / anti-IgG antigen-antibody complex [16]. In RA bone erosions caused by osteoclasts and proteolytic enzymes cause cartilage dissolution [17]. Rheumatoid factors like immunoglobulin $\mathrm{M}$ and $\mathrm{A}$ (IgM \& IgA) are key pathogenic markers [18].

\section{Diagnosis}

Rheumatoid arthritis can be difficult to diagnose in its early stages because the early signs and symptoms mimic those of many other diseases. There is no one blood test or physical finding to confirm the diagnosis. During the physical examination, joints should be checked for swelling, redness and warmth as well as reflexes and muscle strength.

1. Blood tests: People with rheumatoid arthritis often have an elevated erythrocyte sedimentation rate (ESR, or sed rate) or C-reactive protein (CRP), which may indicate the presence of an inflammatory process in the body. Other common blood tests look for rheumatoid factor and anti-cyclic Citrullinated peptide (anti-CCP) antibodies.

2. Imaging tests: X-rays can help to track the progression of rheumatoid arthritis in joints over time. Magnetic Resonance Imaging (MRI) and ultrasound tests can also help to judge the severity of the disease.

\section{Treatment}

The main aim of treatment is focused towards decreasing the disease activity or decreasing the inflamed condition with some remission if possible, along with a minimization of joint destruction and finally improving the physical condition and quality of life. Medications may be prescribed along with lifestyle changes $[19,20]$. Drug is available for treatment of rheumatoid arthritis (Table 1).

\section{Surgery}

If medications fail to prevent or slow joint damage, you and your doctor may consider surgery to repair damaged joints. Surgery may help restore your ability to use your joint. It can also reduce pain and correct deformities. Rheumatoid arthritis surgery may involve one or more of the following procedures:

1. Synovectomy: Surgery to remove the inflamed synovium (lining of the joint). Synovectomy can be performed on knees, elbows, wrists, fingers and hips.

2. Tendon Repair: Inflammation and joint damage may cause tendons around the joint to loosen or rupture. Surgeon may be able to repair the tendons around the joint.

3. Joint Fusion: Surgically fusing a joint may be recommended to stabilize or realign a joint and for pain relief when a joint replacement isn't an option.

4. Total Joint Replacement: During joint replacement 
Table 1: Side Effects of Medication Used in Treatment in Rheumatoid Arthritis

\begin{tabular}{|c|c|c|c|}
\hline S. No. & Therapy & Drugs & Side effect \\
\hline 1 & Over the Counter & $\begin{array}{l}\text { Acetaminophen (Tylenol), Aspirin, } \\
\text { ibuprofen, naproxen. }\end{array}$ & $\begin{array}{l}\text { Stomach upset or nausea, stomach pain, } \\
\text { heartburn, diarrhoea, Stomach ulcer } \\
\text { and bleeding, increased blood pressure, } \\
\text { allergic reaction - hives, facial swelling }\end{array}$ \\
\hline 2 & $\begin{array}{l}\text { Disease-modifying } \\
\text { anti-rheumatic } \\
\text { drugs (DMARDs) }\end{array}$ & $\begin{array}{c}\text { Methotrexate, gold salts, } \mathrm{p} \\
\text { enicillamine, sulfasalazine, and } \\
\text { hydroxychloroquine. Common } \\
\text { combinations of } \\
\text { DMARDs include } \\
\text { methotrexate - hydroxychloroquine, } \\
\text { methotrexate sulfasalazine, } \\
\text { Sulfasalazine - hydroxychloroquine } \\
\text { and } \\
\text { methotrexate- hydroxychloroquine- } \\
\text { sulfasalazine. }\end{array}$ & $\begin{array}{l}\text { Stomach upset, nausea, vomiting, or } \\
\text { diarrhoea liver problems, blood prob- } \\
\text { lems, muscle aches and pain }\end{array}$ \\
\hline 3 & $\begin{array}{l}\text { Non-steroidal } \\
\text { anti-inflammatory } \\
\text { drugs (NSAIDs) }\end{array}$ & $\begin{array}{l}\text { Paracetamol, ibuprofen, naproxen, } \\
\text { meloxicam, etodolac, nabumetone, } \\
\text { sulindac, tolementin, choline magne- } \\
\text { sium salicylate, diclofenac, diflusinal, } \\
\text { indomethicin, ketoprofen, oxaprozin, } \\
\text { and piroxicam. }\end{array}$ & $\begin{array}{l}\text { ·Stomach pain and heartburn, } \\
\text {-Stomach ulcer, heAdache, dizziness, } \\
\text { ringing in the ear, allergic reactions } \\
\text {-rashes, wheezing, and throat swelling. } \\
\text { Liver or kidney problem, high blood } \\
\text { pressure }\end{array}$ \\
\hline 4 & Biological agents & $\begin{array}{c}\text { Tumor necrosis factor alpha (TNFa) } \\
\text { blockers- } \\
\text { etanercept (Enbrel), infliximab } \\
\text { (RemicAde), Adalimumab (Humira), } \\
\text { certolizumab pegol (Cimzia), golim- } \\
\text { umab (Simponi) Monoclonal anti- } \\
\text { bodies against B cells - rituximab } \\
\text { (Rituxan) }\end{array}$ & $\begin{array}{c}\text { Peripheral oedema, heAdache, } \\
\text { fever, muscle aches and pain, } \\
\text { decreased appetite, increased } \\
\text { triglyceride level, insomnia, } \\
\text { abdominal pain, back pain, dizziness, } \\
\text { infusion reactions } \\
\text { low blood pressure, anaphylaxis, cancer, } \\
\text { serum sickness, autoimmune thyroiditis, } \\
\text { arterial and venous blood clot, } \\
\text { congestive heart failure }\end{array}$ \\
\hline
\end{tabular}

surgery, surgeon removes the damaged parts of joint and inserts a prosthesis mAde of metal and plastic.

\section{Herbal drug treatment of RA}

Total of 15 plants with potential anti-arthritic activity have been discussed below-

\section{Harpagophytum procumbens}

Harpagophytum procumbens known as "devils claws" is a plant, originated in Southern Africa, specifically, from the Kalahari Desert and Namibia steppes. Ethanolic extract of Harpagophytum procumbens root has been evaluated for its anti-inflammatory and analgesic activity in rat by Freund's Adjuvant-induced arthritis both in the acute and chronic phases. Behavioural test, body weight, Hot-plate test and paw volume were measured. The results showed that the extract increased the animals 'latency of paws' withdrawal, indicating a protective effect against the pain induced by the thermal stimulus, both in acute and chronic treatments [21].

\section{Bauhinia variegata}

The anti-inflammatory activity of the leaf extract of Bauhinia variegata using three in-vivo animal models: the carrageenan induced rat paw oedema, cotton pellets induced granuloma formation, and Adjuvant induced arthritis in rat were evaluated. Both the ethanol and the petroleum ether fractions obtained from this extract demonstrated activity in all the three bioassays. The activity was found to be more pronounced in the petroleum ether fraction. These bioactivities compared favourably with diclofenac sodium, which was used as positive control, and confirms the traditional usefulness of this plant for the treatment of both acute and chronic inflammatory conditions [22].

\section{Leucas Aspera}


Leucas aspera (La) is traditionally used for analgesic, anti-pyretic, anti-rheumatic, anti-inflammatory and antibacterial treatment and its paste is applied topically to inflamed areas. The chronic anti-inflammatory activity of ethanolic extract of La was investigated using complete Freund's adjuvant arthritis model. A dose of 100 and 200 $\mathrm{mg} / \mathrm{kg}$ exhibited significant anti-inflammatory activity ( $\mathrm{p}$ $<0.001)$. After the treatment, histopathological studies confirmed complete cartilage regeneration and near normal joint [23].

\section{Phyllanthus Amarus}

The aqueous extract of Phyllanthus amarus ( $\mathrm{Pa})$ containing $2.5 \%$ Phyllanthin and hypophyllanthin) was tested against Freund's complete Adjuvant induced arthritic rats. Arthritis assessment, paw volume, joint diameter, mechanical hyperalgesia and nociceptive threshold were measured. The Pa extract significantly decreased the arthritis which was evident with arthritis index, paw volume and joint diameter. It also significantly increased the mechanical hyperalgesia and nociceptive threshold. The histopathology also revealed the control in inflammation with PA [24].

\section{Acalypha indica}

Acalypha indica (Ai) methanol extract was evaluated using three different in-vitro models to explore anti-arthritic potential such as inhibition of protein denaturation, proteinase inhibitory action and anti-hyaluronidase activity. The concentrations of 10 to $200 \mu \mathrm{g} / \mathrm{ml}$ of Ai methanol extract were prepared using dimethyl-sulphoxide (DMSO). Diclofenac was used as the positive control. All in-vitro determinations were done in triplicate. A dose dependent increase in percentage inhibition was observed for all the three models. The inhibitory concentration $\left(\mathrm{IC}_{50}\right)$ was found to be $37 \mu \mathrm{g} / \mathrm{ml}$ in proteinase inhibitory action, 52 $\mu \mathrm{g} / \mathrm{ml}$ for protein denaturation assay; and $18 \mu \mathrm{g} / \mathrm{ml}$ for anti-hyaluronidase activity. Diclofenac offered protective activity at even much lower concentrations compared to Ai methanol extract producing $\mathrm{IC}_{50}$ values of 40 and 13 $\mu \mathrm{g} / \mathrm{ml}$ for protein denaturation and proteinase inhibitory assays. Ai exhibited a very good anti-arthritic activity in all the methods and confirmed its traditional use [25].

\section{Cassia uniflora}

Petroleum ether, ethyl acetate and methanolic extract of Cassia uniflora (Cu) were screened for analgesic by Eddy's hot plate and acetic acid induced writhing, antiinflammatory by carrageenan induced paw oedema and anti-arthritic activity by complete Freund's Adjuvant (CFA) induced arthritis. In complete Freund's adjuvant arthritis model, degree of inflammation was evaluated by hind paw swelling, body weight and biochemical parameters, and supported by radiological analysis. Treatment with extracts of Cu showed significant and dose dependent increase in paw licking time in Eddy's hot plate method. In writhing test, extracts significantly reduced the number of writhes. A dose dependent and significant inhibition of oedema was observed in carrageenan induced paw oedema. Petroleum ether extract at a dose of $100 \mathrm{mg} / \mathrm{kg}$ showed most potent and significant activity which was supported by the result of body weight, biochemical parameters and radiological analysis in CFA arthritic model [26].

\section{Asystasia dalzelliana}

Anti-arthritic activity of ethanolic extract of Asystasia dalzelliana (Ad) leaves was evaluated by Freund's adjuvant induced arthritis model in rats. Paw oedema, changes in organ weight, serum parameters such as Serum Glutamate Oxaloacetate Transaminase (SGOT), Serum Glutamate Pyruvate Transaminase (SGPT) and Alkaline Phosphatise (ALP) were estimated. Hind paw of experimental rats were also subjected for radiographic and histopathological examination for assessing the anti-arthritis potential of ethanolic extract of Ad leaves. The results of the current investigation concluded that extract of dose of $800 \mathrm{mg} /$ $\mathrm{kg}$ possesses is a significant anti-arthritic activity than the lower doses of $200 \mathrm{mg} / \mathrm{kg}$ and $400 \mathrm{mg} / \mathrm{kg}$. The observed anti-arthritis activity of extract may be due to the presence of phytoconstituents such as alkaloid and Flavonoids. Ad for its possible anti-arthritic activity by Human Red Blood Cell (HRBC) membrane stabilization and inhibition of protein denaturation method were evaluated. Methanolic extract upon the column chromatography yielded five fractions named (Ad-01, Ad-02, Ad-03, Ad-04, and Ad-05) and were screened for their anti-arthritic activity. Among the five fractions tested, Ad-3 and Ad-4 showed good antiarthritic activity when compared with standard Diclofenac sodium. The maximum membrane stabilization of Ad-3 and Ad-4 fraction was found to be at $71.64 \%$ and $94.68 \%$ (average) respectively. The inhibition of Ad-3 and Ad-4 fraction's protein denaturation was found to be $52.84 \%$ and $64.56 \%$ respectively. Therefore, the studies supported the use of active constituents from Ad leaves in treating rheumatoid arthritis [27].

\section{Asparagus racemosus}

The hydro alcoholic extract of Asparagus racemosus (Ar) roots in-vivo 200 and $400 \mathrm{mg} / \mathrm{kg}$ were tested for its anti-inflammatory and anti-arthritic activity against 
carrageenan induced paw oedema methodology which is used to induce inflammation whereas Freund's Complete Adjuvant (FCA) is used to induce arthritis. The extract reduces paw volume, joint diameter, and arthritic score estimates the haematological parameters like Red Blood Cell (RBC), White Blood Cell (WBC), ESR and percentage of haemoglobin $(\mathrm{Hb})$ for assessing arthritic activity. Their investigation concluded that the hydro alcoholic extract of Ar roots showed significant anti-inflammatory and antiarthritic activity [28].

\section{Sida rhombifolia}

Sida rhombifolia (Sr) has been used from prehistoric times for the treatment of gout in Indonesia. Effect of SR stem and root extracts using Adjuvant induced arthritis model in experimental rats were evaluated. Extract was found to normalize the altered levels of haematological parameters. The elevated rate of erythrocyte sedimentation was also significantly reduced [29].

\section{Genkwa flos}

Antioxidant effect of Genkwa flos (Gf) flavonoids on Freund's adjuvant induced rheumatoid arthritis in rats. To evaluate the anti-oxidative effects of flavonoids aglycones (FA) isolated from the GF were tested for its anti-arthritic activity by Adjuvant induced arthritis. FA significantly decreased paw oedema, arthritic score, and increased body weight. The results conclude that FA significantly decreased arthritis in a rat model through anti-oxidant and haematological modulatory mechanism. The Gf flavonoids may have clinical potential for the treatment of rheumatoid arthritis [30].

\section{Hemidesmus Indicus}

The protective effects of hydro alcoholic and its fractions from roots of Hemidesmus indicus (Hi) have been investigated by complete Freund's adjuvant model. Rats treated with hydro alcoholic extract $(450 \mathrm{mg} / \mathrm{kg})$, ethyl acetate $(75 \mathrm{mg} / \mathrm{kg})$, chloroform $(60 \mathrm{mg} / \mathrm{kg}$ ) and residual fraction $(270 \mathrm{mg} / \mathrm{kg}$ ) showed significant decrease in physical and biochemical parameters compared with arthritic model rats. Hydro alcoholic extract and its ethyl acetate fraction of $\mathrm{Hi}$ showed significantly higher antiarthritic activity than chloroform and residual fraction. Histopathological analysis demonstrated that both of hydro alcoholic extract and its ethyl acetate fraction had comparable anti-arthritic activity with methotrexates [31].

J Bone Biol Osteoporosis, 4(1): 43-50 (2018) ,

\section{Azima retracantha}

Azima tetracantha (At) is known as Kundali in Ayurvedic medicine and also called uppimullu in Kannada. There are reports that the leaves juice is efficient against toothache and earache. In Indian tribes, leaves paste of At is used to treat snakebites. Friedelin, a compound isolated from At leaves was investigated for Adjuvant-induced arthritis activity in Wistar rats and $54.5 \%$ of paw thickness in rats was noted [32].

\section{Cinnamomum zeyllanicum}

Anti-inflammatory and anti-arthritic activity of type-A procyanidine polyphenols (TAPP) have been reported from bark of Cinnamomum zeyllanicum (CZ) in rats. TAPP showed significant anti-inflammatory effect in Carrageenan induced paw oedema model. TAPP treatment in established arthritic rats showed significant reversal of Adjuvant-induced arthritis with respect to body drop, ankle diameter, arthritic score, and serum C-reactive protein levels. Haematological parameters like RBC, WBC, $\mathrm{ESR}, \mathrm{Hb} \%$ were also evaluated for assessing anti-arthritic activity. Their investigation concluded that TAPP from CZ have potential anti-inflammatory and anti-arthritic activity [33].

\section{Wedelia calendulacea}

The effect of Wedelia calendulacea (Wc) leaves has been investigated alone or in combination with sub therapeutic dose of Methotrexate $(1 \mathrm{mg} / \mathrm{Kg})$ It has salvaging, anti oxidative stress, anti- arthritic action and cardio protective action with Methotrexate. Rats were induced arthritis by sub plantar injection of $0.1 \mathrm{~mL}$ CFA. Various haematological, (RBC, WBC, Hb, ESR and RA Factor) biochemical (Homocecytein, TNF-a, IL-2 and CRP) parameters and tissue (Superoxide dismutase, Catalase and Lipid peroxidation of aorta) parameters were measured before initiation and after completion of treatment in all groups. Methanolic fraction of methanolic extract (Me-OH/Me-OH) of Wc showed significant anti-arthritic activity in CFA induced arthritic animals [34].

\section{Holarrhena pubescens}

Holarrhena pubescens (HP) is an Indian traditional medicinal plant. It is commonly known as 'kurchi' in India. Ethanolic extract of dried seeds of HP were investigated for their anti-inflammatory and anti-arthritic activities. HP (400 $\mathrm{mg} / \mathrm{kg}$, p.o.) extract showed maximum (74.07 \%) inhibition against carrageenan-induced rat paw oedema, 62.63\% inhibition in granuloma formation and $77.95 \%$ inhibition 
against Adjuvant induced arthritic oedema in rats when compared with Indomethacin standard drug [35].

\section{Conclusion}

Traditional herbal medicines used for the treatment of rheumatoid arthritis are used in various tribal/rural cultures worldwide. The herbal medicinal plants, which have been discussed, show promising role as anti-arthritic agents. The presently available synthetic drugs in the market are not only doing economic exploitation but also associated with adverse effects. The synthetic drugs include NSAIDs and DMARDs like cyclophosphamide, intramuscular gold, sulfasalazine, Methotrexate had the side effects like stomach ulcers, gastrointestinal tract bleeding, kidney, liver damage and hypertension. There is a need to identify the active principals of these herbal medicines as potential chemotherapeutic agents and monitor the safety of these active constituents. A large number of herbal plants described in this review article clearly demonstrated the importance of herbal plants in the treatment of rheumatoid arthritis.

\section{References}

1. Chitme HR, Patel NP. Antiarthritis Activity of Aristolochia Bracteata Extract in Experimental Animals. The Open Natural Products Journal. 2009;2(1):6-15. doi: http:// dx.doi.org/10.2174/1874848100902010006

2. ANTI-INFLAMMATORY AND ANTIARTHRITIC POTENTIAL OF AMMANIA BACCIFERA LINN . http://www.ijpbs.net/ issue-3/60.pdf.

3. Chunxia C, Peng Z, Huifang P, Hanli R, Zehua H, Jizhou W. Extracts of Arisaema rhizomatum C.E.C. Fischer attenuate inflammatory response on collagen-induced arthritis in BALB/c mice. Journal of Ethnopharmacology. 2011;133(2):573-582. doi: http://dx.doi.org/10.1016/j. jep.2010.10.035

4. Babushetty V, Sultanpur MC (2012) Evaluation of antiarthritis activity of Asystasia dalzelliana leaves. Int J Pharma Biol Arch 3:377-382.

5. Ngoc DDT, Catrina Al, Lundberg $\mathrm{K}$, et al. Inhibition by Artocarpus tonkinensis of the Development of Collagen-Induced Arthritis in Rats. Scandinavian Journal of Immunology. 2005;61(3):234-241. doi: http://dx.doi. org/10.1111/j.1365-3083.2005.01560.x

6. Mazumder PM, Mondal A, Sasmal D, Arulmozhi S, Rathinavelusamy P. Evaluation of antiarthritic and immunomodulatory activity of Barleria lupulina. Asian Pacific Journal of Tropical Biomedicine. 2012;2(3):S1400-S1406. doi: http://dx.doi.org/10.1016/
S2221-1691(12)60425-0

7. . BR, . VR, . MG, et al. Effect of Bauhinia variegata on Complete Freund `s Adjuvant Induced Arthritis in Rats. Journal of Pharmacology and Toxicology. 2007;2(5):465472. doi: http://dx.doi.org/10.3923/jpt.2007.465.472

8. Kumar V, Cortan R. Basic Pathology. 10th edition Elsevier 7:136-139.

9. Majithia V, Geraci SA. Rheumatoid Arthritis: Diagnosis and Management. The American Journal of Medicine. 2007;120(11):936-939.doi: http://dx.doi.org/10.1016/j. amjmed.2007.04.005

10. Siddiqui D, Amir A, Poonam V, et al. Arthritis database: A composite web interface for anti- arthritic plants. Journal of Medicinal Plants Research. 2011;5:2457-2461.

11. Maxwell JR, Gowers IR, Moore DJ, Wilson AG. Alcohol consumption is inversely associated with risk and severity of rheumatoid arthritis. Rheumatology. 2010;49(11):2140-2146. doi: http://dx.doi.org/10.1093/ rheumatology/keq202

12. Scott DL, Wolfe F, Huizinga TW. Rheumatoid arthritis. The Lancet. 2010;376(9746):1094-1108. doi: http:// dx.doi.org/10.1016/S0140-6736(10)60826-4

13. Weissmann G. The pathogenesis of rheumatoid arthritis. Bull NYU Hosp Jt Dis. 2006;64(1-2):12-15.

14. Isler P, Vey E, Zhang JH, Dayer JM. Cell surface glycoproteins expressed on activated human $T$ cells induce production of interleukin-1 beta by monocytic cells: a possible role of CD69. Eur Cytokine Netw. 1993;4(1):15-23.

15. Epstein FH, Harris ED. Rheumatoid Arthritis: Pathophysiology and Implications for Therapy. New England Journal of Medicine. 1990;322(18):1277-1289. doi: http://dx.doi.org/10.1056/NEJM199005033221805

16. Immunopathogenesis of rheumatoid arthritis. The American Journal of Medicine. 1979;67(6):961-970. doi: http://dx.doi.org/10.1016/0002-9343(79)90636-3

17. Nepom GT, Byers P, Seyfried C, et al. HLA Genes associated with rheumatoid Arthritis. Identification of susceptibility alleles using specific oligonucleotide probes. Arthritis \& Rheumatism. 1989;32(1):15-21. doi: http://dx.doi.org/10.1002/anr.1780320104

18. van der Linden MPM, van der Woude D, IoanFacsinay A, et al. Value of anti-modified citrullinated vimentin and third-generation anti-cyclic citrullinated peptide compared with second-generation anticyclic citrullinated peptide and rheumatoid factor in predicting disease outcome in undifferentiated arthritis and rheumatoid arthritis. Arthritis \& Rheumatism. 
2009;60(8):2232-2241. doi: http://dx.doi.org/10.1002/ art.24716

19. Huizinga TWJ, Pincus T. In the clinic. Rheumatoid arthritis. Ann Intern Med. 2010;153(1):ITC1-1-ITC1-15; quiz ITC1-16. doi: http://dx.doi.org/10.7326/00034819-153-1-201007060-01001

20. Edwards JCW, Szczepański L, Szechiński J, et al. Efficacy of B-Cell-Targeted Therapy with Rituximab in Patients with Rheumatoid Arthritis. New England Journal of Medicine. 2004;350(25):2572-2581. doi: http://dx.doi. org/10.1056/NEJMoa032534

21. Andersen ML, Santos EH., Seabra M de LV, da Silva AA., Tufik S. Evaluation of acute and chronic treatments with Harpagophytum procumbens on Freund's adjuvantinduced arthritis in rats. Journal of Ethnopharmacology. 2004;91(2-3):325-330. doi: http://dx.doi.org/10.1016/j. jep.2004.01.003

22. Saha S. In Vivo Study for Anti-inflammatory Activity of Bauhinia variegata L. Leaves. Pharmaceutical Crops. 2011;2(1):70-73. doi: http://dx.doi. org/10.2174/2210290601102010070

23. Kripa KG, Chamundeeswari D, Thanka J, Uma Maheswara Reddy C. Modulation of inflammatory markers by the ethanolic extract of Leucas aspera in adjuvant arthritis. Journal of Ethnopharmacology. 2011;134(3):1024-1027. doi: http://dx.doi.org/10.1016/j.jep.2011.01.010

24. Mali SM, Sinnathambi A, Kapase CU, Bodhankar SL, Mahadik KR. Anti-arthritic activity of standardised extract of Phyllanthus amarus in Freund's complete adjuvant induced arthritis. Biomedicine \& Aging Pathology. 2011;1(3):185-190. doi: http://dx.doi. org/10.1016/j.biomag.2011.09.004

25. R J, K. RT. EVALUATION OF ANTI ARTHRITIC ACTIVITY OF THE ROOT EXTRACT OF ACALYPHA INDICA LINN. USING IN VITRO TECHNIQUES. International Journal of Phytopharmacy. 2013;2(6). doi: http://dx.doi. org/10.7439/ijpp.v2i6.36

26. Chaudhari SS, Chaudhari SR, Chavan MJ. Analgesic, anti-inflammatory and anti-arthritic activity of Cassia uniflora Mill. Asian Pacific Journal of Tropical Biomedicine. 2012;2(1):S181-S186. doi: http://dx.doi.org/10.1016/ S2221-1691(12)60155-5

27. Kumar S, Kumar V (2011) In-vitro Antiarthritic activity of isolated fractions from methanolic extract of Asystasia dalzelliana leaves. Asian J Pharm Clin Res 4:5253.

28. Mittal S (2013) In-vivo anti-inflammatory and antiarthritic activity of Asparagus racemosus linn roots. Int J Pharm Sci Res 4:2652-2658.

29. Limmy TP (2012) Anti-inflammatory and anti-oxidant properties of Sida rhombifolia stems and roots in Adjuvant induced arthritic rats. Immunopharmacol immunotoxicol 34:326-336

30. Zhang C-F, Zhang S-L, He X, et al. Antioxidant effects of Genkwa flos Flavonoids on Freud's adjuvantinduced rheumatoid arthritis in rats. Journal of Ethnopharmacology. 2014;153(3):793-800. doi: http:// dx.doi.org/10.1016/j.jep.2014.03.046

31. Mehta A, Sethiya NK, Mehta C, Shah G. Anti-arthritis activity of roots of Hemidesmus indicus R.Br. (Anantmul) in rats. Asian Pacific Journal of Tropical Medicine. 2012;5(2):130-135. doi: http://dx.doi. org/10.1016/S1995-7645(12)60011-X

32. Antonisamy $\mathrm{P}$, Duraipandiyan $\mathrm{V}$, Ignacimuthu $\mathrm{S}$. Anti-inflammatory, analgesic and antipyretic effects of friedelin isolated from Azima tetracantha Lam. in mouse and rat models: Anti-inflammatory effect of Friedelin. Journal of Pharmacy and Pharmacology. 2011;63(8):1070-1077. doi: http://dx.doi.org/10.1111 /j.2042-7158.2011.01300.

33. Sachinveta I, subhash L (2013) Anti-inflammatory and anti- arthritic activity of type-a procyanidine polyphenols from bark of Cinnamomum zeyllanicum in rats. FSHW 2:59-67

34. Panchal A, Patel R, Bhandari A. Anti-arthritic and synergetic activity of Wedelia Calendulacea linn with methotrexate in Adjuvant induced arthritis with cardioprotective activity in rat. http:// pharmacologyonline.silae.it/files/archives/2011/ vol3/018.panchal.pdf.

35. Saha S, Subrahmanyam E. Evaluation of antiinflammatory activity of ethanolic extract of seeds of Holarrhena pubescens Wall. https:// innovareacademics.in/journal/ijpps/Vol5Issue3/7271. pdf.

Copyright: (c) Nimesh et al. This is an Open Access article distributed under the terms of the Creative Commons Attribution License, which permits unrestricted use, distribution, and reproduction in any medium, provided the original work is properly cited. 